\title{
Journal of Health Sciences
}

\section{The impact of organizational culture on patient satisfaction}

Aida Pilav1,2*, Zaim Jatić3,4

${ }^{1}$ Clinical Center of the University of Sarajevo, Sarajevo, Bosnia and Herzegovina, ${ }^{2}$ Faculty of Health Sciences, University of Sarajevo, Sarajevo, Bosnia and Herzegovina, ${ }^{3}$ Medical Center of the Sarajevo Canton, Sarajevo, Bosnia and Herzegovina, ${ }^{4}$ Faculty of Medicine, University of Sarajevo, Sarajevo, Bosnia and Herzegovina

\begin{abstract}
Introduction: Managing organizational culture has been increasingly viewed as a lever for health care improvement. The aim of this study was to investigate the correlation between the type of organizational culture and patient satisfaction in the selected health care centers in the Federation of Bosnia and Herzegovina (FBIH).
\end{abstract}

Methods: We conducted a cross-sectional survey in two municipal primary health care (PHC) centers in the $\mathrm{FBIH}$, referred as Primary health care $(\mathrm{PHC})$ center $\mathrm{A}$ and Primary health care $(\mathrm{PHC})$ center $\mathrm{B}$. A validated questionnaire, known as the Organizational Culture Assessment Instrument (OCAI), was used for the assessment of organizational culture. The questionnaire was distributed among the family health care teams at the two PHCs. Simultaneously, we carried out a survey about patient satisfaction among patients during their visits to the family health care teams.

Results: We observed the differences in the type of the organizational culture between the health care centers. The hierarchical culture was found the dominant culture in PHC center A, whereas the market culture was the dominant culture in PHC center B. Also, the statistical significance (t test) was recorded in the overall patient satisfaction in the health care center with the dominated hierarchical culture followed by the clan culture (PHC center A).

Conclusions: Considering the lack of similar surveys in Bosnia and Herzegovina, we believe that this study might be a good starting point for education of human resource managers in health care.

Keywords: Organizational culture; patient satisfaction; primary health care

\section{INTRODUCTION}

A number of transitional countries, including Bosnia and Herzegovina, have been facing challenges in

\footnotetext{
*Corresponding author: Aida Pilav,

Clinical Center of the University of Sarajevo, Sarajevo, Bosnia and Herzegovina, Bolnička 25, 71000 Sarajevo,

Phone: +387 33205 517. E-mail: idanap@bih.net.ba
}

Submitted: 15 February 2017/Accepted: 04 April 2017

DOI: https://doi.org/10.17532/jhsci.2017.411 their health care systems, such as: Declining of health standards, a lack of financial resources, the inability of organizational and management structures to carry on efficient and effective provision of health services, and disharmonized needs and demands for health care. Despite this, the health sector primarily aims to provide everyone with quality and constant health care, based on the health condition, in accordance with generally accepted professional and ethical principles. Therefore, urgent activities 
should be introduced in quality standards aimed at building the system of quality control and quality improvement (1).

Cultural aspects of healthcare organizations are considered important in determining the quality of patient care, either through fostering excellence or contributing to failure $(2,3)$. Organizational culture is one of the cultural aspects in an organization that is determined by the main characteristics, such as structure, typology, power and manifestation through internal and external organizational aspects. According to Edgar Schein, organizational culture is defined as a pattern of shared basic assumptions that a group has learned as it solved its problems of external adaptation and internal integration, that has worked well enough to be considered valid, and, therefore, to be taught to new members as the correct way to perceive, think, and feel in relation to those problems (4).

A great number of authors argue that understanding of organizational culture might be key for successful strategic improvements in an organization (5-9). In addition, there are claims that a successful adaptation to changes that initiate reforms in health care institutions might depend on their organizational cultures. Therefore, the correlation between organizational culture and performance in health care institutions and professional organizations should be continuously studied.

This paper is based on the premise that organizational culture in the health care system in the FBIH has not been considered a serious and systematic issue. Primary health care (PHC) was chosen as a research site since considerable health care reforms were implemented in PHC.

The aim of this study was to investigate several points, including: 1) the type of organizational culture in the municipal PHCs in the FBIH, 2) the level of acceptance of the actual organizational culture by the medical staff of the surveyed PHCs, and 3 ) how the type of the actual organizational culture influences patient satisfaction.

\section{METHODS}

We conducted a cross-sectional survey in the two municipal $\mathrm{PHC}$ centers in the $\mathrm{FBiH}$ in autumn
2015. Inclusion criteria included the PHC centers in the municipalities with an average population in the $\mathrm{FBiH}$ (30.000 to 40.000 inhabitant), but in two different geographical locations and cultural environment in order to compare the organizational culture and patient satisfaction levels. The selected PHC centers were from two different cantons in the $\mathrm{FBiH}$, with equal PHC organizational models, pursuant to the common Act on Health Care. For the purpose of conducting this survey, the PHC centers were marked as PHC A and B. The survey was conducted anonymously with a prior approval of the managerial structure in the PHC centers, as a census which included all members of family health care teams in these PHC centers. The response rate was $100 \%$ (Table 1). The OCAI method developed by Cameron and Quinn (10) was used to assess organizational culture in the PHCs. The OCAI is based on a theoretical model known as the Competing Values Framework (CVF). The CVF recognizes four types of organizational culture: Hierarchy, clan, adhocracy and market culture. The aim of the CVF is to help organizations identify their current and preferred culture. Through the questionnaire, the respondents were asked to rank the actual organizational culture and their future preferences. The questions were based on six key dimensions of organizational culture, as follows: Dominant characteristics of organization, organizational leadership, management of employees, organization glue, strategic emphasis and criteria of success. The scores were calculated for each of the six key dimensions.

Simultaneously, we conducted a survey among the patients during their visits to the family health care teams, in the course of one day. The sample included 100 patients randomly selected in the PHCs. Prior to the survey, the patients were determined only by sex and the equal ratio of male and female patients. The age structure was a random choice. To investigate patient satisfaction, we used a modified questionnaire about patient satisfaction (SullivanLuallin Healthcare Consulting, San Diego, California). The questionnaire was divided into six sections: Appointment, staff, communication, visit to providers, facilities and overall satisfaction. Each section was ranked from 1 (poorly) to 5 (excellent). There were no ethical or regulatory constraints reported. 
TABLE 1. Health care professionals - respondents, by age, sex and professional structure

\begin{tabular}{lccccccc}
\hline Health care & Physicians & Nurses & F & M & Average age & $\begin{array}{c}\text { Average duration } \\
\text { of work }\end{array}$ & $\begin{array}{c}\text { Familiarity with the term of } \\
\text { organizational culture (\%) }\end{array}$ \\
\hline A & 9 & 22 & 3 & 28 & 44.8 & 21.7 & 50 \\
B & 6 & 8 & 2 & 12 & 44.6 & 20.9 & 35.7 \\
\hline
\end{tabular}

TABLE 2. Patient satisfaction in PHC center $A$ and $B$ - by sections

\begin{tabular}{lcc}
\hline Sections & $\begin{array}{c}\text { Health center } \mathrm{A} \\
\text { score }\end{array}$ & $\begin{array}{c}\text { Health center } \mathrm{B} \\
\text { score }\end{array}$ \\
\hline $\begin{array}{l}\text { Appointment } \\
T \text { test, } P>0.005\end{array}$ & 4.32 & 3.31 \\
Staff & & \\
$\quad T$ test, $P>0.05$ & 4.53 & 3.78 \\
$\begin{array}{l}\text { Communication } \\
T \text { test, } P>0.005\end{array}$ & 4.16 & 3.36 \\
$\begin{array}{l}\text { Visits to } P H C \text { providers } \\
T \text { test, } P>0.005\end{array}$ & 4.42 & 3.86 \\
$\begin{array}{l}\text { Facility } \\
T \text { test, } P=0.1\end{array}$ & 3.66 & 3.83 \\
Overall satisfactions & 4.45 & \\
$T$ test, $P>0.005$ & & 3.85 \\
\hline
\end{tabular}

\section{Statistical analysis}

The data obtained from the questionnaires were processed using the Statistical Package for Social Sciences (SPSS), Version 22.0. A parametric t test was used to compare the obtained data.

\section{RESULTS}

The main demographic characteristic of the respondents from the PHC centers are shown in Table 1. The respondents were the staff of the family health care teams in two municipalities. The mean age of the respondents was 44.8 and 44.6 years, while the mean duration of service was 21.7 and 20.9 years, respectively. When asked whether they were familiar with the term of organizational culture, $50 \%$ of the respondents from PHC center $\mathrm{A}$ and approximately $36 \%$ from PHC center B answered positively.

\section{Dominant organizational culture in PHC centers}

PHC center A

Dominant organizational culture in PHC center A was the hierarchy culture (32.63 points), followed by the clan culture ( 31.89 points), the market

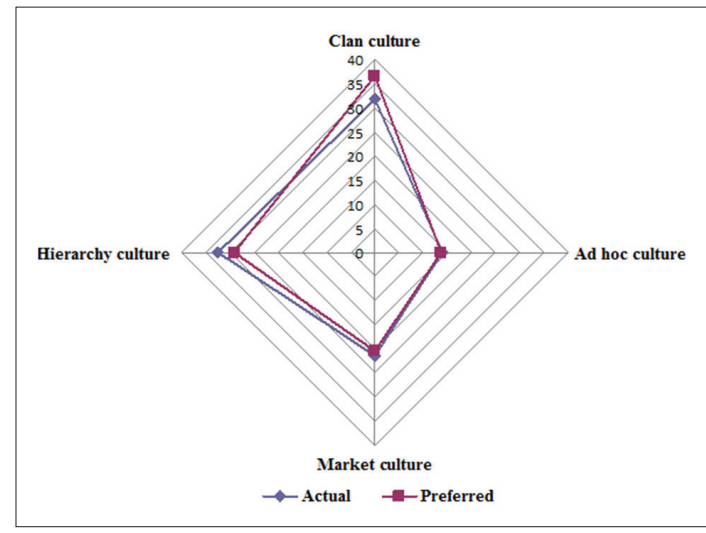

FIGURE 1. The actual and preferred organizational culture in PHC center $A(p>0.05)$

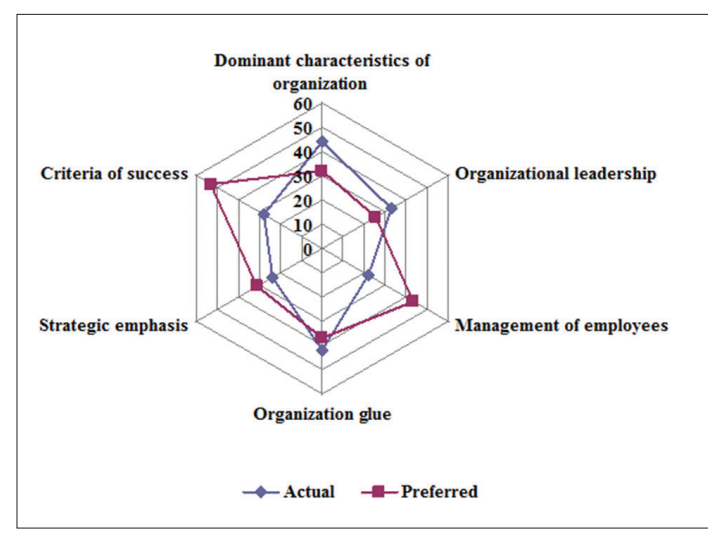

FIGURE 2. The key dimensions of the clan culture in $\mathrm{PHC}$ center A-actual and preferred

culture (21.51 points), and finally the ad hoc culture (Figure 1).

In addition to the assessment of the actual culture, the respondents also ranked the preferred culture. The main preference in PHC center A was stronger oriented towards the clan culture (Figure 2).

PHC center B

Dominant organizational culture in $\mathrm{PHC}$ center B was the market culture (32.92 points), followed by the hierarchy culture ( 26.55 points), and the ad 
hoc culture (26.55 points). In PHC center B, the respondents preferred the clan culture. The discrepancy between the actual and preferred culture was almost 19 points (Figure 3).

A great discrepancy among the key dimensions in the actual and the preferred organizational culture was detected, except in organizational leadership (Figure 4).

\section{Patient satisfaction}

Patients were asked to rank (Likert scale, 1-5 points) several sections in relation to their visits to the PHC centers. The ranked sections included appointment, staff, communication, visits to PHC providers, facilities and overall satisfaction.

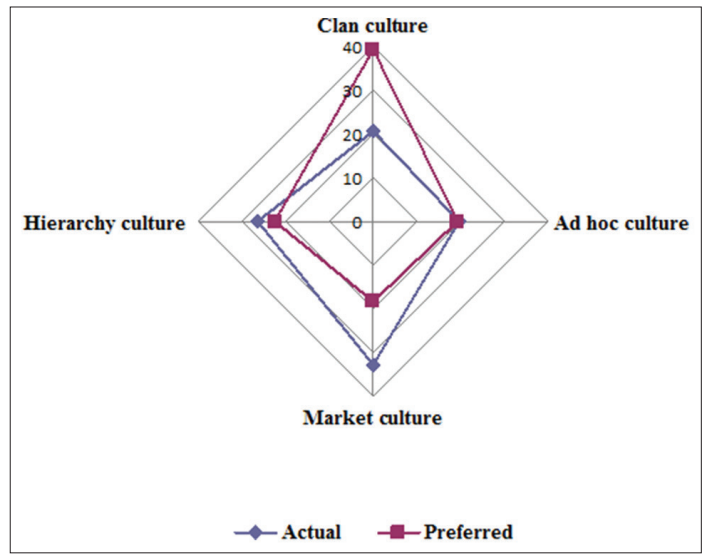

FIGURE 3. The actual and preferred organizational culture in $\mathrm{PHC}$ center $\mathrm{B}$

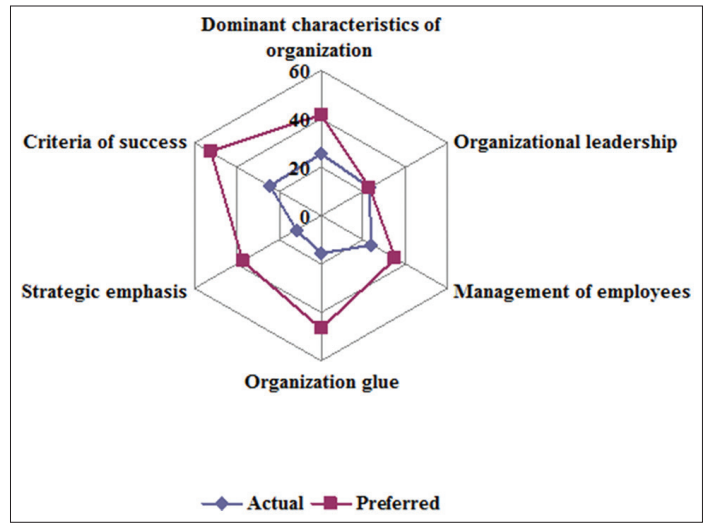

FIGURE 4. The key dimensions of the clan culture in PHC center $\mathrm{B}$ - actual and preferred
Facilities in PHC center A were ranked the lowest (3.66), while the relationship with staff was ranked the highest (4.53). The respondents were less satisfied with appointments in PHC center B (3.31), whereas the visits to $\mathrm{PHC}$ providers were ranked the highest (3.86).

The statistical significance in the scoring of PHC centers was recorded for sections of appointment, communication, visits to PHC providers and overall patient satisfaction. Each of these domains was higher scored in the health care center with dominated clan culture.

A significant difference was detected in the overall patient satisfaction ( $\mathrm{t}$ test, $\mathrm{p}<0.005$ ) between the PHC centers (Table 2).

\section{DISCUSSION}

Our findings shows how the type of organizational culture in the PHC affects patient satisfaction. To assess organizational culture, we used the OCAI which identifies four organizational archetypes.

In $\mathrm{PHC}$ center $\mathrm{A}$, the actual organizational culture was the hierarchy culture. In the hierarchy culture, the organization is considered a formal and structured work environment, with formal policies and rules to maintain smooth operations. The second ranked type of culture was the clan culture. The main features of the clan culture are loyality, team work and cohesion. Both are internally oriented culture, typical for the health care sector. Due to the specific topic, they are mainly oriented towards internal management and organizations as well as professional issues related to the health care of patients. The third type of culture was the market culture (21.51 points), which is result-oriented. The low ranking of the market culture might indicate that health care organizations are less competitive and profit-oriented. The last ranked type of culture is the ad hoc culture, which is based on supporting of individual initiatives and freedom.

Furthermore, the preferred culture in PHC center A was the clan culture. This findings showed that health care practitioners were oriented towards more flexibility, people-oriented environment, innovation, and professional freedom. This seems to be a clearly visible trend. There are six main dimensions 
that explain the type of organizational culture. These dimensions are not comprehensive, but may illustrate a real frame of the dominant organizational culture. The analysis of the key dimensions of the preferred clan culture showed the necessity of changing aspects of the staff management and criteria of success.

In PHC center $\mathrm{A}$, the dominating culture was the hierarchy culture (32.63 points) followed by the clan culture (31.89 points).

In $\mathrm{PHC}$ center $\mathrm{B}$, the actual organizational culture was the market culture. In the market culture, organization is considered result-oriented. The major concerns are task completion, reputation and success. This pattern was followed by the hierarchy culture in which organizations are considered formal and structured work places. In PHC center B, the need for more clan culture was detected in the respondents. They prefered the health care sector that encouraged more personal freedom in their field of specialization, and more personal responsibilities and individual initiatives. In addition, the clan culture is very important for it emphasizes long-term benefits of human resource development and assignes the great importance to cohesion and morale. Success is defined in terms of sensitivity to customers and concern for people. The organization recognizes the importance of teamwork, participation, and consensus.

Statistical significant difference was observed in patient satisfaction between the two PHC centers. Patient satisfaction was more evident in $\mathrm{PHC}$ center A with the dominant hierarchy culture.

A survey conducted in the Dutch health care system in 2007 showed that the current organizational culture was internally oriented. More specifically, the health care sector seemed preoccupied with issues of internal governance and organization, as well as professional matters. The friendly clan culture and the structured hierarchy culture scored the highest in this survey, which is similar with our results. In fact, the clan culture is commonly represented in health care. It is based on strongly shared values, and health care practitioners have shown great interest for its further representation (11).

A recent US survey highlighted that identification of clinic-specific culture archetypes associated with provider satisfaction can help in redesigning the evidence-based practice. Effective methods for changing the organizational culture are recommended. With knowledge of the types of cultures within health care organizations, managers may be able to adapt both their messages about transformation and their management of the process of change to be more compatible within dividual clinic's cultures, reducing barriers to the change (12).

There is an increasing international interest in managing organizational culture as a lever for health care improvement (13-15). Introducing the culture change in health care has been increasingly perceived as essential for health care reforms. It is very important to induce seriously functional consequences through the regular monitoring. Furthermore, in case of compiling the type of organizational culture with general satisfaction of patients, the picture might become clearer. There is some evidence suggesting that organizational culture may be a relevant factor in health care performance, yet articulating the nature of that relationship has proven complicated (16).

This paper should be considered to be a pilot study, and a basis for regular monitoring of organizational culture in health care institutions (17). A small number of respondents were involved in the survey. A considerably greater sample size is being required to unravel the relationship between organizational culture and performance, and patient satisfaction.

\section{CONCLUSIONS}

Regular measurements of basic aspects of organizational culture and their assessment in health organizations are necessary to perform to improve health care by establishing the quality standards of outcome. These results might help in identification of organizational culture as a basis for initiating possible changes of organizational culture.

\section{ACKNOWLEDGMENTS}

We acknowledge the contribution of the medical staff from the two PHC centers for their kind assistance in conducting of the survey. 


\section{CONFLICT OF INTEREST}

The authors declare no conflict of interest.

\section{REFERENCES}

1. World Health Organization. Health 21 - health for all in the $21^{\mathrm{s}} \mathrm{century}$. Copenhagen WHO Regional Office for Europe, 1999.

2. Braithwaite J, Westbrook MT, Travaglia JF, Hughes C. Cultural and associated enablers of, and barriers to, adverse incident reporting. Qual Saf Health Care 2010;19(3):229-233.

https://doi.org/10.1136/qshc.2008.030213.

3. Mannion R, Davies HT, Marshall MN. Cultures for Performance in Health Care. London: Open University Press, 2005.

4. Schein EH. Organizational Culture. American Psychologist 1990; 45(2): 109-119.

https://doi.org/10.1037/0003-066X.45.2.109.

5. Ouchi WG. Theory Z: How American Business Can Meet the Japanese Challenge. Boston: Addison-Wesley, 1981.

6. Pascale RT, Athos AG. The Art of Japanese Management. Applications for American Executives. New York: Simon \& Schuster, 1982.

7. Peters TJ, Waterman RH. In Search of Excellence: Lessons from America's Best-Run Companies. New York: HarperCollins, 1982.

8. Deal TE, Kennedy AA. Corporate Cultures: The Rights and Rituals of Corporate Life. New York: Perseus Books Publishing, L.L.C., 1982.

9. Deal TE, Kennedy AA. Culture: A New Look Through Old Lenses. Journal of Applied Behavioral Sciences 1983;19:498-506. https://doi.org/10.1177/002188638301900411.

10. Cameron KS, Quinn RE. Diagnosing and Changing Organizational Culture Based on the Competing Values Framework. The Jossey-Bass Business and Management Press. San Francisco: John Wiley \& sons, Inc., 2006.

11. Health care sector examined with the OCAI. Diagnosis: Dissatisfied: A National Survey in the Netherlands, OCAI online, March 2010. M.M.W. Bremer MscBA.

12. Scammon DL, Tabler J, Brunisholz K, Gren LH, Kim J, Tomoaia-Cotisel A., et al. Organizational culture associated with provider satisfaction. J Am Board Fam Med. 2014; 27(2):219-28.

https://doi.org/10.3122/jabfm.2014.02.120338.

13. Ford R, Bach S, Fottler M. Methods of measuring patient satisfaction in health care organizations. Health Care Manage Rev.1997; 22:74-89 https://doi.org/10.1097/00004010-199704000-00009.

14. Institute of Medicine. Crossing the Quality Chasm: A new health system for the $21^{\text {st }}$ century. Washington, DC: National Academies Press, 2001.

15. Bertakis KD, Azari R. Patient-centered care is associated with decreased health care utilization. J Am Board Fam Med. 2011; 24:229-39.

https://doi.org/10.3122/jabfm.2011.03.100170.

16. Scott T, Mannion R, Marshall M, Davies H. Does organizational culture influence health care performance? A review of the evidence. Journal of health services research policy 2003; 8(2):105-17. https://doi.org/10.1258/135581903321466085.

17. Gené-Badia J, Jodar-Solà G, Peguero-Rodríguez E, Contel-Segura JC, Moliner-Molins $C$. The EFQM excellence model is useful for primary health care teams. Family Practice. 2001;18(4):407-09.

https://doi.org/10.1093/fampra/18.4.407. 